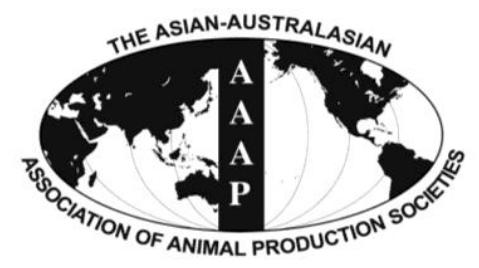

Asian-Aust. J. Anim. Sci.

Vol. 25, No. 5 : 597 - 605

May 2012

www.ajas.info

http://dx.doi.org/10.5713/ajas.2012.r.01

\title{
Vitamin C Nutrition in Cattle
}

\author{
T. Matsui* \\ Division of Applied Biosciences, Graduate School of Agriculture, Kyoto University, \\ Kitashirakawa Oiwake-cho, Sakyo-ku, Kyoto, 606-8502, Japan
}

\begin{abstract}
Domestic animals, including ruminants, can synthesize vitamin C (VC) in their liver; as such, the dietary requirement for VC has not been confirmed in these animals. The adequacy of VC has been evaluated by quantifying VC levels in plasma, but the reported values in bovine plasma have been widely variable. Plasma VC concentration is decreased by heat stress, hepatic lesions, fattening, and infectious diseases such as mastitis in cattle. Therefore, VC supplementation is potentially beneficial for cattle with low plasma VC concentration. This review discusses the methods for determination of plasma VC concentration in cattle, VC nutrition, and the efficacy of VC supplementation in calves, dairy cattle, and beef cattle. Additionally I propose a reference range for plasma VC concentration in Japanese Black cattle. (Key Words: Vitamin C, Calf, Dairy Cattle, Beef Cattle)
\end{abstract}

\section{INTRODUCTION}

Vitamin $\mathrm{C}(\mathrm{VC})$ is the generic term for all compounds showing the biological activity of ascorbic acid (AsA). The majority of VC exists as AsA in the bodies of animals, and AsA can be reversibly oxidized to dehydroascorbic acid (DAsA) (McDowell, 1989).

Dietary VC is essential for some animals, including humans, subhuman primates, and guinea pigs, but many other mammals, such as ruminants, swine, horses, dogs, and cats, can synthesize AsA from glucose in the liver; in addition, many birds can synthesize AsA in the liver or in the kidney (Comb, 2008). As such, the dietary requirement for $\mathrm{VC}$ has not been confirmed in the animals that can synthesize AsA. However, incidences of scurvy, a typical sign of VC deficiency, have been reported in calves (Cole et al., 1944) and in cows (Duncan et al., 1944). Additionally, ruminants may be more prone to $\mathrm{VC}$ deficiency than other domestic animals in cases when the synthesis of AsA is impaired (McDowell, 1989) because dietary VC is easily degraded in the rumen (Knight et al., 1941; Nockels, 1988; MacLeod et al., 2003).

The function of $\mathrm{VC}$ has been mainly investigated in humans and in laboratory animals, and is related to its reversible oxidation and reduction characteristics. Vitamin $\mathrm{C}$ serves as a cofactor for some oxygenases, which are

* Corresponding Author: T. Matsui. Tel: +81-75-753-6055, Fax: +81-75-753-6344, E-mail: matsui@kais.kyoto-u.ac.jp involved in the synthesis of collagen, catecholamines, and carnitine, and in the metabolism of xenobiotics, cholesterol, and tyrosine (Comb, 2008). Vitamin C is also an important water-soluble antioxidant (Frei et al., 1989) that prevents the oxidation of protein, DNA and nitric oxide. Further, VC is involved in the recycling of vitamin E; $\alpha$-tocopherol scavenges proxy radicals and reacts with them to form a $\alpha$ tocopheroxyl radical, which is then recycled back to $\alpha$ tocopherol by VC (May et al., 1998). Furthermore, VC increases iron bioavailability through the reduction of ferric ions to ferrous ions (Wollenberg and Rummel, 1987).

Immune function is affected by VC in several ways; VC protects neutrophils against oxidative stress induced by free radicals associated with the oxidative burst (Wolf, 1993), stimulates interferon production, which protects cells against viral attack (Siegel, 1975), and chemotactic responses of leukocytes (Goetzl et al., 1974). Vitamin C also prevents the formation of potent carcinogens, such as nitrosamine (Archer et al., 1975).

Vitamin $\mathrm{C}$ enhances the in vitro differentiation of several mesenchyme-derived cells, including myoblasts (Nandan et al., 1990), chondrocytes (Gerstenfeld and Landis, 1991), osteoblasts (Sugimoto et al., 1986), and adipocytes (Kawada et al., 1990). We also reported that physiological levels of $\mathrm{VC}$ promoted the differentiation of preadipocytes derived from bovine adipose tissue (Figure 1, Torii et al., 1998). These actions of VC are likely mediated by the synthesis of collagenous extracellular matrix, as extracellular matrix is known to affect the differentiation of 


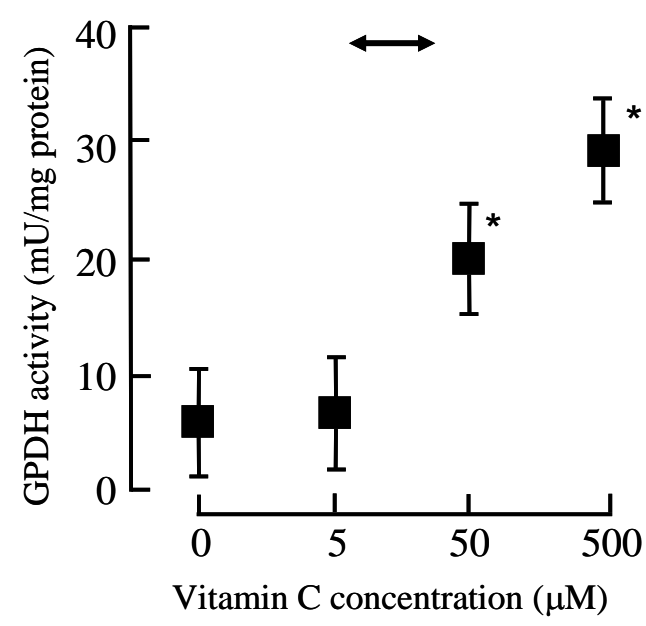

Figure 1. Effect of vitamin $\mathrm{C}$ on adipocyte differentiation from bovine stromal vascular cells derived from perirenal adipose tissue (Torii et al., 1998). Mean \pm SE for cultures derived from three different donors. * Mean differs from that of the control culture (no vitamin $\mathrm{C}$ added) $(\mathrm{p}<0.05)$. Vitamin $\mathrm{C}$ was supplied as ascorbyl-2-phosphate. The specific activity of gycerol-3phosphate dehydrogenase (GPDH) was used as a biochemical index of differentiation. The arrow shows the range of the plasma vitamin C concentration observed in beef cattle (see Figure 4).

some cells (Franceschi, 1992). A recent study showed that VC stimulated osteoblast differentiation by promoting the nuclear translocation of the transcription factor nuclear factor-E2-related factor-1 (Nrf1) that can bind an antioxidant-responsive element (Xing et al., 2007). Therefore, it is likely that $\mathrm{VC}$ mediates the expression of some genes through its effect on the intracellular redox state, which also likely mediates VC action in cell differentiation.

\section{ASSESSMENT OF VITAMIN C ADEQUACY}

The adequacy of $\mathrm{VC}$ can be evaluated by analysis of $\mathrm{VC}$ or AsA in plasma, serum, leukocytes, or urine. In addition, AsA is reversibly oxidized to DAsA in the bodies of animals (McDowell, 1989). Thus, both forms are biologically active as VC; therefore, AsA or VC (AsA+ DAsA) can be evaluated to assess VC adequacy. In dairy cattle, the plasma DAsA level is approximately $10 \%$ of the plasma VC (Weiss, 2001). Therefore, plasma VC concentration is not substantially different from plasma AsA concentration.

Hatipoglu and Muglali (1995) reviewed reports measuring plasma VC or AsA concentration in cattle and observed that the reported concentrations varied widely. In some studies, there may have been problems with methods used to determine plasma VC concentration. The degradation of $\mathrm{VC}$ during sample storage is well recognized, but less attention has been paid to $\mathrm{VC}$ degradation in plasma samples for VC determination (Wang et al., 1995). In fact, $\mathrm{VC}$ concentration in bovine plasma substantially decreased within $3 \mathrm{~d}$ even if the plasma samples were stored at $-30^{\circ} \mathrm{C}$ (Haiying et al., 2003). Thus, plasma AsA and VC concentrations should be determined immediately after blood collection. Alternatively, it is recommended that the plasma samples are treated with a reducing reagent such as dithioerythritol or dithiothreitol during storage because the addition of these reducing agents enhances the stability of $\mathrm{VC}$ in cattle plasma. It must be noted that treatment with these agents reduces DAsA into AsA, and thus VC, but not AsA, will consequently be measured when plasma samples are treated with these agents.

Many experiments have used colorimetric methods for determining plasma AsA concentration in ruminants (Hidiroglou et al., 1977; Palludan and Wegger, 1984; Cummins and Brunner, 1991; Takahashi et al., 1999). These studies applied various colorimetric reactions based on AsA oxidation. Some of the colorimetric methods have been shown to exhibit poor specificity and to be positively affected by the presence of reducing substances in plasma (Wang et al., 1995). There are also methods using high performance liquid chromatograph (HPLC) for the determination of plasma VC or AsA concentration. We compared $\mathrm{VC}$ or AsA concentrations in cattle plasma using an HPLC with a spectrophotometric detector after dithioerythritol treatment and using the $\alpha, \alpha$ '-dipyridyl method, a colorimetric method, respectively. We found that the colorimetric method yielded plasma AsA concentrations that were substantially higher than the plasma VC concentrations determined by the HPLC method (Haiying et al., 2003). We also determined plasma VC concentrations in fattening cattle with both the HPLC method mentioned above and another HPLC method that uses an electrochemical detector after treatment with dithiothreitol (Umegaki et al., 1999); the measured values did not differ between the two methods (unpublished data). Thus, I consider the HPLC methods to be reliable methods for determining VC concentration in bovine plasma.

It was reported that the supplementation of ascorbyl-2polyphosphate did not increase urinary $\mathrm{VC}$ concentration in lactating dairy cows, but it did increase plasma VC concentration (Weiss, 2001). However, we reported that urinary excretion of $\mathrm{VC}$, expressed as the ratio to creatinine, increased in beef cows as dietary AsA coated by a hydrogenated soybean oil increased (Figure 2, Padilla et al., 2007a). Therefore, similar to plasma VC concentrations, urinary excretion of $\mathrm{VC}$ likely demonstrates the adequacy of $\mathrm{VC}$ in cattle.

\section{VITAMIN C SUPPLEMENTATION AND CIRCULATING VITAMIN C CONCENTRATION IN CATTLE}

Vitamin C is easily degraded in the rumen (Knight et al., 


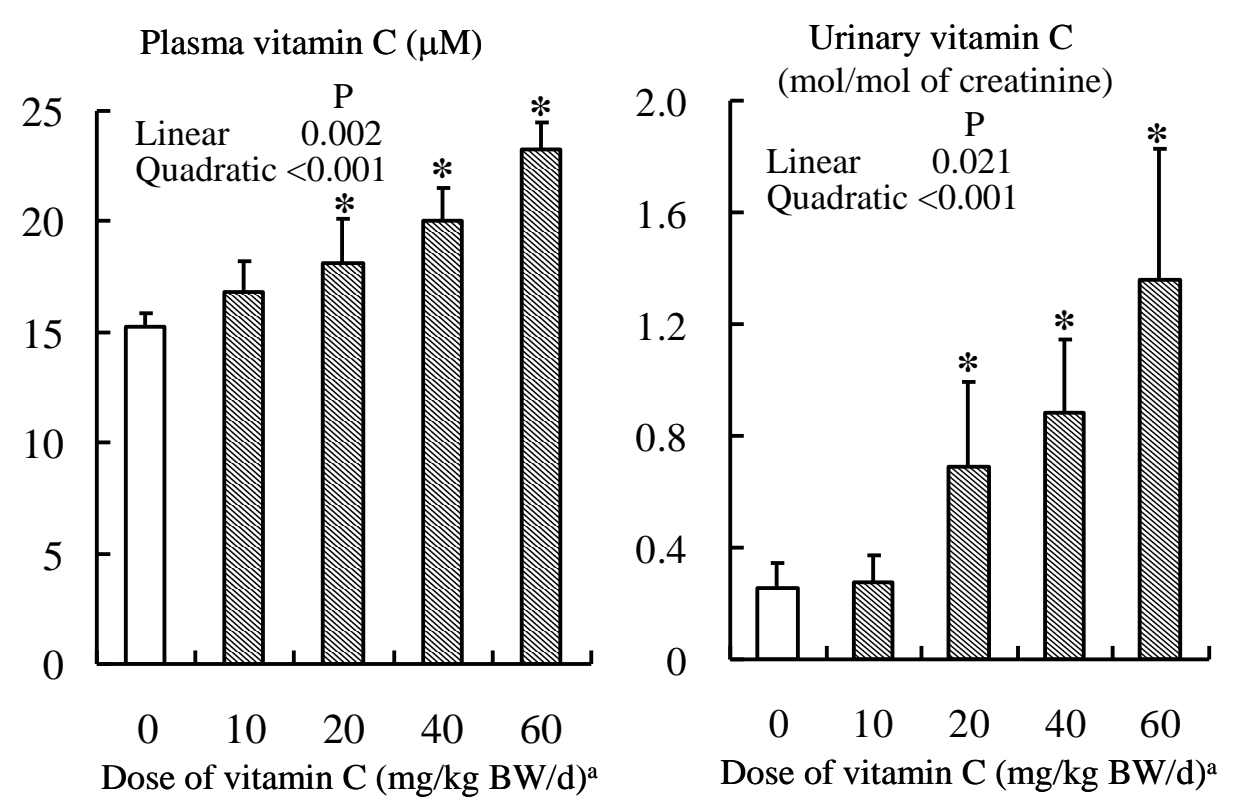

Figure 2. Effect of vitamin $\mathrm{C}$ supplementation on plasma concentration and urinary excretion of vitamin $\mathrm{C}$ in fattening beef cows. Mean \pm SE for five cows. ${ }^{*}$ The mean differs from the cows not receiving the vitamin $\mathrm{C}$ preparation $(\mathrm{p}<0.05)$. ${ }^{\mathrm{a}}$ Ascorbic acid coated with hydrogenated soybean oil.

1941; Nockels, 1988; MacLeod et al., 2003). Accordingly, ruminally protected VC preparations are available for dietary supplementation in cattle. Plasma AsA concentration was increased by supplementation with $80 \mathrm{~g} / \mathrm{d}$ of ascorbyl2-polyphosphate (20 g AsA/d, $54 \mathrm{mg} \mathrm{AsA} / \mathrm{kg} \mathrm{BW/d}$ ) in dairy heifers (MacLeod et al., 1999). Weiss (2001) reported that graded levels of dietary ascorbyl-2-polyphosphate $(0 \mathrm{~g}$, $3 \mathrm{~g}$, or $30 \mathrm{~g} \mathrm{AsA} / \mathrm{d}$ ) linearly increased plasma AsA concentration in lactating cows. Plasma AsA concentration was increased by supplementation of ascorbyl-2-phosphate (10 g AsA/d, $38 \mathrm{mg} \mathrm{AsA} / \mathrm{kg} \mathrm{BW/d}$ ) in heifers (Tyler and Cummins, 2003). Hidiroglou (1999) reported that $40 \mathrm{~g} / \mathrm{d}$ of AsA coated with ethyl cellulose increased plasma AsA concentration in cows. We investigated the effect of graded levels of dietary AsA coated with a hydrogenated soybean oil ( 0 to $36 \mathrm{~g} \mathrm{AsA} / \mathrm{d}, 0$ to $60 \mathrm{mg} \mathrm{AsA} / \mathrm{kg} \mathrm{BW/d}$ ) on plasma concentration and urinary excretion of $\mathrm{VC}$ in fattening beef cows, and our results indicated that these parameters increased as dietary VC increased (Figure 2, Padilla et al., 2007a); the lowest dose affected neither the plasma VC concentration nor urinary $\mathrm{VC}$ excretion, but the plasma $\mathrm{VC}$ concentration and urinary $\mathrm{VC}$ excretion increased with increasing doses of AsA supplementation.

Hidiroglou et al. (1997) compared the efficacy of several VC preparations, such as powdered AsA, AsA coated with silicon or ethyl cellulose, and ascorbyl-2polyphosphate, in sheep and demonstrated that AsA coated with silicon most effectively increased plasma AsA concentration. We found that the efficacy of AsA preparations coated with hydrogenated oil was different among the preparations, with varying effects on plasma VC concentration (unpublished data). Thus, these results suggest that the availability of VC is substantially different among the preparations.

\section{VITAMIN C IN CALVES}

It was reported that hepatic AsA concentration was high in neonatal calves and greatly decreased thereafter (Watts, 1950). Plasma VC concentrations were higher in neonatal calves than in their dams; however, the plasma VC levels then rapidly decreased such that the VC concentrations in 6week-old and 3-month-old calves were low compared to that of their dams (Bouda et al., 1980). Low plasma AsA concentrations were also reported in 10-wk-old calves, with gradual recovery of AsA levels over time (Palludan and Wegger, 1984). Based on these results, Palludan and Wegger (1984) suggested that hepatic AsA synthesis was low in calves and that VC supplementation was required for growing calves until liver AsA synthesis was fully developed. In addition, the incidence of scurvy was reported in weaned calves (Cole et al., 1944). Thus, it was recommended that milk replacers should contain supplemental VC at a level of 2,000 mg/d (MacLeod et al., 2003). However, a precise experiment using radiolabeled AsA as a tracer indicated that calves were able to synthesize a sufficient amount of AsA (Toutain et al., 1997). This study also showed that plasma AsA concentrations were substantially higher in neonatal calves than in their dams but that the plasma AsA levels in the calves decreased to the level of their dams within $2 \mathrm{~d}$ and was stable thereafter.

In general, the changes in plasma AsA concentration 
during growth were largely variable among calves; in contrast, the changes in plasma AsA concentration during growth of monozygotic twin calves showed uniformity, suggesting that there are strong genetic effects on AsA synthesis in calves (Palludan and Wegger, 1984). Genetic variation may affect the essentiality for VC supplementation in calves. In addition, calves housed in metal pens had lower plasma AsA concentrations than calves housed in calf hutches, suggesting that environmental stressors increase the metabolic demand for $\mathrm{VC}$, resulting in decreased plasma AsA concentrations (Cummins and Brunner, 1991).

Vitamin C supplementation has been reported to prevent diarrhea in calves (Cummins and Brunner, 1989; Seifi et al., 1996; Sahinduran and Albay, 2004). Calves fed a diet containing VC had less nasal and ocular discharge (EicherPruiett et al., 1992). However, these reports failed to show a positive effect of VC supplementation on neutrophil function (Eicher-Pruiett et al., 1992) or an antibody response to vaccination (Cummins and Brunner, 1989). Hidiroglou et al. (1995) reported that VC supplementation consistently elevated the concentrations of AsA in the plasma of healthy calves, but plasma IgG concentrations and antibody responses to vaccination were not significantly affected.

As mentioned above, the metabolic demand of $\mathrm{VC}$ in calves is likely influenced by environmental conditions (Cummins and Brunner, 1991). Thus, it is possible that VC supplementation is conditionally essential in calves. Further studies are necessary to investigate the beneficial effects of VC supplementation on the health of calves.

\section{VITAMIN C IN LACTATING COWS}

The demand for glucose is elevated in lactating dairy cows because of the large production of lactose in the mammary gland. Glucose is the sole precursor of AsA in animal body. MacLeod et al. (1999) suggested that high producing cows were considered to have low AsA synthesis resulting from the high demand for glucose, especially during the early lactation period. On the other hand, Santos et al. (2001) reported that plasma AsA concentration was not affected by the stage of lactation, and they suggested that endogenous AsA production met the $\mathrm{VC}$ demand in lactating cows. Ketosis is a disease related to the high rate of glucose utilization in the mammary gland and the inability of cows to meet the glucose demand through its supply (Baird, 1982). We investigated plasma VC concentration in cows during the early lactation period and observed that plasma glucose concentrations were lower in ketotic cows than in control cows, whereas plasma VC concentrations did not differ between the control and the ketotic cows (Padilla et al., 2005). These results indicate that the concentration of plasma $\mathrm{VC}$ is not related to the incidence of ketosis in the early lactation period and suggest that ketotic cows have the ability to produce sufficient levels of VC to meet their VC demand in the early lactation period despite glucose insufficiency.

Fatty liver is a major metabolic disorder observed in many dairy cows during the early lactation period. Excess lipids are stored as triacylglycerol in the liver and are associated with decreased metabolic function of the liver (Bobe et al., 2004). Severe fatty liver particularly affects the integrity and function of hepatocytes and, therefore, causes necrosis and cellular leakage, resulting in increased concentrations of liver enzymes and bile constituents in the plasma (Bobe et al., 2004). Hepatic lesions induced by nitrosamine were reported to decrease plasma VC concentration in dogs (Strombeck et al., 1983). We postulated that plasma VC concentration was decreased in lactating cows suffering from hepatic lesion and investigated the relationship between plasma VC concentration and serum diagnostic biochemical makers in lactating dairy cows at high risk for fatty liver, i.e., cows diagnosed with ketosis, and clinically normal cows from the same herds. We observed that plasma VC concentrations were lower in the cows that concurrently had low levels of total cholesterol and albumin (potential markers for hepatic function) and high levels of alkaline phosphatase and aspartate aminotransferase (markers for hepatic lesion) (Padilla et al., 2007b). Therefore, hepatic malfunction likely decreases plasma VC concentration by suppressing VC production. Alternatively, the consumption of $\mathrm{VC}$ may be increased in cows with fatty liver because fatty liver induces oxidative stress, as indicated by lipid peroxidation (Mudron et al., 1999). One of the primary approaches used to prevent fatty liver is to counteract the oxidative damage to the liver (Bobe et al., 2004). Thus, VC supplementation may ameliorate the severity of fatty liver in lactating cows.

Mastitis decreases plasma VC concentrations in dairy cows (Weiss et al., 2004; Kleczkowski et al., 2005; Ranjan et al., 2005). Some researchers investigated the efficacy of parenteral VC administration as a potential mastitis treatment. Vitamin $\mathrm{C}$ treatment reduced the severity of acute mammary inflammation, which was induced by intramammary infusion of endotoxin, when $25 \mathrm{~g}$ of AsA was administered by intravenous injection twice within $8 \mathrm{~h}$ of the endotoxin challenge (Chaiyotwittayakun et al., 2002). Another experiment showed that subcutaneous injection of AsA $(25 \mathrm{mg} / \mathrm{kg} \mathrm{BW})$ stimulated the recovery from clinical mastitis in cows treated with antimicrobials (Naresh et al., 2002). Dietary supplementation with ascorbyl-2polyphosphate $(30 \mathrm{~g} / \mathrm{d})$ decreased milk somatic cell count in dairy cows with mastitis induced by the endotoxin challenge but did not improve neutrophil function in blood (Weiss and Hogan, 2007). However, plasma AsA concentration did not correlate with milk somatic cell count 


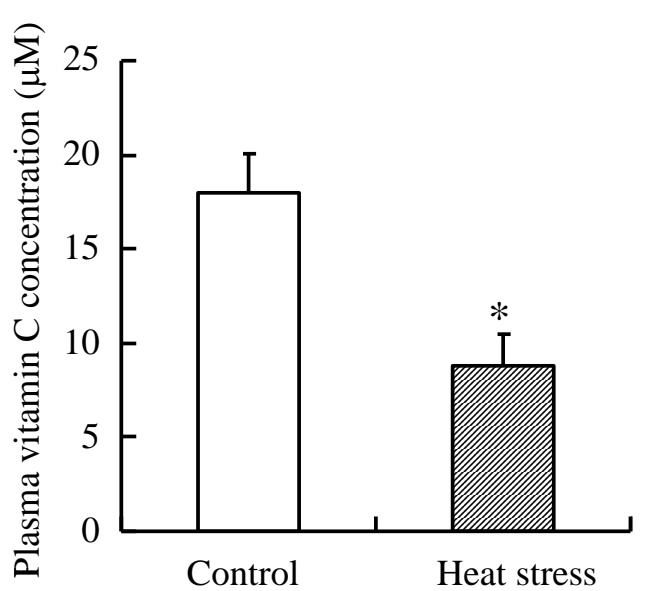

Figure 3. Effect of heat exposure on plasma vitamin $\mathrm{C}$ concentration in lactating cows. Mean \pm SE for four cows. $*$ The mean differs from the control cows $(\mathrm{p}<0.05)$. The cows were kept in an air-conditioned room with the ambient temperature set at $18^{\circ} \mathrm{C}$ during the control treatment and at $28^{\circ} \mathrm{C}$ during the heatstressing treatment.

or metabolic profiles in lactating cows (Santos et al., 2001). Vitamin C supplementation may enhance the recovery from mastitis or alleviate mastitis in lactating cows with low plasma VC concentration; the mechanisms mediating these effects remain unclear.

A high ambient temperature compromises the ability of lactating dairy cows to dissipate heat, resulting in heat stress. Heat stress increases production of oxygen-derived free radicals (Mitchell and Russo, 1983), which may have various deleterious effects, including the incidence of some diseases (Lykkesfeldt and Svendsen, 2007) and reproductive problems in dairy cows (Miller and Brezezinska-Slebodzinska, 1993). We found that heat stress decreased the plasma $\mathrm{VC}$ concentration in lactating cows (Figure 3, Padilla et al., 2006); plasma VC concentration was decreased by $50 \%$ with controlled high-ambient temperature. In addition, we also showed that the plasma $\mathrm{VC}$ concentration of lactating cows was significantly lower in the summer than in the autumn (Padilla et al., 2006), which was further supported by the report of Tanaka et al. (2008). Vitamin C supplementation was reported to recover the performance of poultry and weaned pigs exposed to heat stress (McKee and Harrison, 1995; De-Rodas et al., 1998; Sahin et al., 2003), suggesting that VC supplementation may be beneficial to VC-producing animals under heat stress. To my knowledge, the beneficial effects of VC have not been reported in lactating dairy cows under heat stress. However, dietary supplementation with VC may alleviate the adverse effects of heat stress in dairy cows.

\section{VITAMIN C IN BEEF CATTLE}

As mentioned above, some researchers have studied VC nutrition in dairy cows. However, few studies of VC nutrition have been conducted with beef cattle. Takahashi et al. (1999) reported that plasma AsA concentrations decreased during fattening in cattle. We measured plasma VC concentrations using HPLC in clinically healthy Japanese Black cattle, including 135 calves, 238 fattening heifers, 524 fattening steers, 127 replacement heifers and breeding but not lactating cows (Figure 4). This survey showed that the individual variations in plasma VC concentrations were substantial and that sex did not affect plasma $\mathrm{VC}$ concentrations in growing and fattening cattle. The plasma VC concentrations were stable by 13.4 mo of age in these cattle (22.5 \pm 3.3 (mean $\pm \mathrm{SD}) \mu \mathrm{M}$ ) but gradually decreased thereafter. On the other hand, plasma VC concentrations did not change with ageing in replacement heifers and dry cows $(22.7 \pm 2.1 \mu \mathrm{M})$, similar to growing cattle. These results show that plasma VC concentration is decreased by fattening but not by chronological age. Obesity is well recognized to induce oxidative stress (Styskal et al., 2011), and plasma VC concentration is inversely related to the percentage of body fat in humans (Johnston et al., 2007). Thus, fattening per se can be considered as an oxidative stressor that decreases plasma VC concentration by enhancing VC consumption.

Analysis of the pooled data from our survey demonstrated that the plasma VC concentration was $22.6 \pm 2.8 \mu \mathrm{M}(3.98 \pm 0.50 \mathrm{mg} / \mathrm{L})$ in cattle excluding fattening cattle older than 13.4 mo of age. The VC concentration that we observed in our pooled cattle data is similar to concentrations reported by previous studies that used HPLC for $\mathrm{VC}$ analysis in apparently healthy dairy cows as follows: $3.40 \mathrm{mg} / \mathrm{L}$ (Weiss, 2001), $4.03 \mathrm{mg} / \mathrm{L}$ (Weiss et al., 2004) and $3.12 \mathrm{mg} / \mathrm{L}$ (Padilla et al., 2006). Another research has shown that plasma AsA concentration in apparently healthy dairy cows was 3.11 to $3.45 \mathrm{mg} / \mathrm{L}$ (Hidiroglou, 1999). From our data, I propose that the reference range for plasma VC concentration is between 17.1 and $28.2 \mu \mathrm{M}$ ( 3.00 and $4.98 \mathrm{mg} / \mathrm{L}$, mean $\pm 1.96 \times \mathrm{SD}$ ) in Japanese Black cattle, except during the fattening period. As mentioned above, the smallest dose of $\mathrm{VC}$ supplementation did not affect plasma VC concentration $(16.8 \mu \mathrm{M})$ and urinary $\mathrm{VC}$ excretion in beef cows but urinary $\mathrm{VC}$ excretion increased when plasma VC concentration reached $18.1 \mu \mathrm{M}$ (Figure 2). Therefore, the threshold plasma concentration for urinary excretion is probably between $16.8 \mu \mathrm{M}$ and $18.1 \mu \mathrm{M}$. I consider that urinary $\mathrm{VC}$ excretion is restricted in cattle when VC is deficient. When VC supply is sufficient, plasma $\mathrm{VC}$ concentration becomes above the excretion threshold and the excretion of $\mathrm{VC}$ increases. Notably, plasma VC concentration did not decrease during the hot season in Japanese Black steers and heifers (unpublished data). It is reasonable that the reduction in plasma $\mathrm{VC}$ concentration during the hot season is observed in lactating dairy cattle 


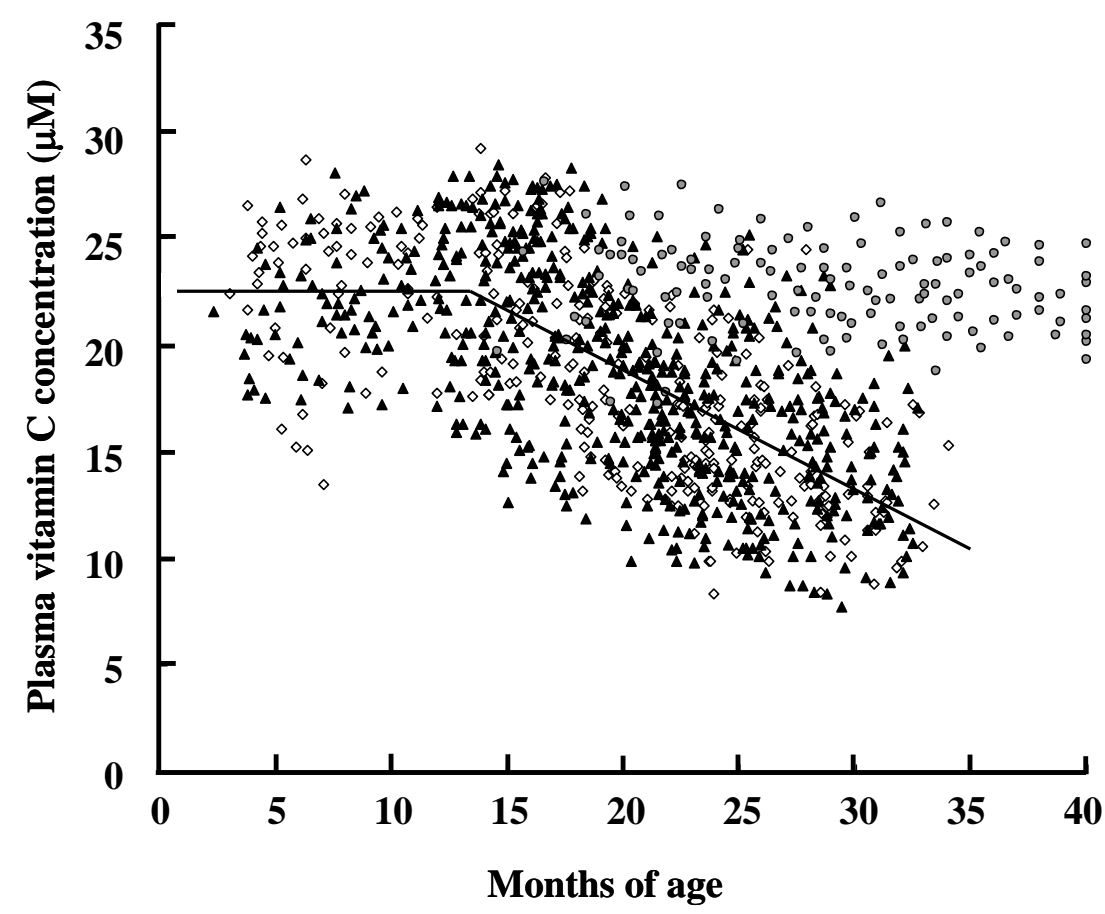

Figure 4. Relationship between plasma vitamin $C$ concentrations and age in beef cattle. Female calves and heifers $(\diamond)$, castrated male calves and steers $(\boldsymbol{\Delta})$, and replacement heifers and dry cows $(O)$. The regression lines were evaluated using the Non Linear Regression Procedure of SAS in all cattle except for replacement heifers and dry cows; $\mathrm{Y}(\mu \mathrm{M})=22.5$ when $\mathrm{X}(\mathrm{mo}) \leq 13.4 ; \mathrm{Y}(\mu \mathrm{M})=-0.556 \mathrm{X}(\mathrm{mo})$ +29.9 when $X(\mathrm{mo}) \geq 13.4$, $\mathrm{p}<0.0001$.

but not in beef cattle because increased sensitivity to the effects of heat in lactating cows compared to non-lactating cows is well recognized (Araki et al., 1984).

Traditionally, highly marbled beef is a delicacy for many Japanese people. Beef marbling is determined by the degree of fat deposition in the muscle. The size and number of adipocytes in muscle increase during fattening (Cianzio et al., 1985). These results imply that differentiation and fat accumulation of adipose cells are important factors in the development of beef marbling. As mentioned above, we reported that physiological levels of VC stimulated the differentiation of preadipocytes derived from bovine adipose tissue (Figure 1). Thus, I consider that VC supplementation is potentially beneficial for producing highly marbled beef.

Although many Japanese researchers examined the effect of dietary VC preparations on beef marbling in Japanese Black cattle, consistent outcomes have not been obtained. The absence of a significant effect resulting from these treatments may be due to the small number of cattle used in these experiments. Hirooka (2009) reevaluated the effects of VC supplementation in published reports and his meta-analysis showed that VC supplementation significantly increased beef marbling in Japanese Black cattle. In addition, many of these experiments did not measure plasma $\mathrm{VC}$ concentrations during the $\mathrm{VC}$ supplementation; therefore, it is not known whether the doses of $\mathrm{VC}$ were sufficient to affect VC nutrition, i.e., to recover plasma VC concentrations during fattening. Furthermore, plasma VC concentrations showed substantial differences among individuals, and approximately $20 \%$ of cattle had a plasma VC concentration above the lower limit of the reference range during the late fattening period (older than 25 mo of age; Figure 4). Thus, VC supplementation may not be useful for fattening cattle with relatively high plasma VC concentrations. I hypothesize that the efficacy of VC supplementation on beef marbling is conditional.

Vitamin $\mathrm{C}$ supplementation in fattening cattle was reported to improve the firmness and texture of the beef (Oohashi et al., 2000; Mori et al., 2006). However, the mechanisms that indicate how VC supplementation affects the firmness and texture of beef remain unclear.

\section{CONCLUSION}

Although the adequacy of $\mathrm{VC}$ can be assessed by plasma VC or AsA concentration, attention must be paid to prevent AsA degradation during sample storage. HPLC methods are reliable for determining $\mathrm{VC}$ concentration in cattle plasma because of their specificity. Plasma VC concentration is decreased by heat stress, hepatic lesions, fattening and infectious diseases such as mastitis in cattle. Further research is needed to clarify whether VC supplementation is beneficial for cattle that exhibit low 
plasma VC levels.

\section{REFERENCES}

Araki, C. T., R. M. Nakamura, L. W. G. Kam and N. Clarke. 1984. Effect of lactation on diurnal temperature patterns of dairy cattle in hot environments. J. Dairy Sci. 67:1752-1760.

Archer, M. C., S. R. Tannenbaum, T. Y. Fan and M. Weisman. 1975. Reaction of nitrite with ascorbate and its relation to nitrosamine formation. J. Natl. Cancer Inst. 54:203-205.

Baird, G. D. 1982. Primary ketosis in the high-producing dairy cow: clinical and subclinical disorders, treatment, prevention, and outlook. J. Dairy Sci. 65:1-10.

Bobe, G., J. W. Young and D. C. Beitz. 2004. Pathology, etiology, prevention, and treatment of fatty liver in dairy cows. J. Dairy Sci. 87:3105-3124.

Bouda, J., P. Jagos, R. Dvorak and J. Ondrova. 1980. Vitamin E and $\mathrm{C}$ in the blood plasma of cows and their calves fed from buckets. Acta Vet. Brono 49:53-58.

Chaiyotwittayakun, A., R. J. Erskine, P. C. Bartlett, T. H. Herd, P. M. Sears and R. J. Harmont. 2002. The effect of ascorbic acid and L-histidine therapy on acute mammary inflammation in dairy cattle. J. Dairy Sci. 85:60-67.

Cianzio, D. S., D. G. Whitehurst, D. C. Beitz and H. L. Self. 1985. Adipose tissue growth and cellularity: changes in bovine adipocyte size and number. J. Anim. Sci. 60:970-976.

Cole, C. L., R. A. Rasmussen and F. Thorp. 1944. Dermatosis in the ears, neck and shoulders in young calves. Vet. Med. 39:204-211.

Combs, G. F. 2008. Vitamin C. In: The vitamins: fundamental aspects in nutrition and health, third edition (Ed. G. F. Combs) Academic Press, San Diego, CA, USA. pp. 235-263.

Cummins, K. A. and C. J. Brunner. 1989. Dietary ascorbic acid and immune response in dairy calves. J. Dairy Sci. 72:129-134.

Cummins, K. A. and C. J. Brunner. 1991. Effect of calf housing on plasma ascorbate and endocrine and immune function. J. Dairy Sci. 74:1582-1588.

De-Rodas, B. Z., C. V. Maxwell, M. E. Davis, S. Mandali, E. Broekman and B. J. Stoecker. 1998. L-ascorbyl-2polyphosphate as a vitamin $\mathrm{C}$ source for segregated and conventionally weaned pigs. J. Anim. Sci. 76:1636-1643.

Duncan, C. W., C. F. Huffman, R. Mitchell, Jr. and J. T. Reid. 1944. Symptom of scurvy observed in a herd of cattle. J. Dairy Sci. 24:636.

Eicher-Pruiett, S. D., J. L. Morrill, F. Blecha, J. J. Higgins, N. V. Anderson and P. G. Reddy. 1992. Neutrophil and lymphocyte response to supplementation with vitamins $\mathrm{C}$ and $\mathrm{E}$ in young calves. J. Dairy Sci. 75:1635-1642.

Franceschi, R. T. 1992. The role of ascorbic acid in mesenchymal differentiation. Nutr. Rev. 50:65-70.

Frei, B., L. England and B. N. Ames. 1989. Ascorbate as an outstanding antioxidant in human blood plasma. Proc. Natl. Acad. Sci. USA 86:6377-6381.

Gerstenfeld, L. C. and W. J. Landis. 1991. Gene expression and extra-cellular matrix ultrastructure of a mineralizing chondrocyte cell culture system. J. Cell Biol. 112:501-513.

Goetzl, E. J., S. I. Wasserman, I. Gigli and K. F. Austen. 1974. Enhancement of random migration and chemotactic response of human leukocytes by ascorbic acid. J. Clin. Invest. 53:813818.

Hatipoglu, F. S. and H. Muglali. 1995. Ascorbic acid concentrations in ruminal fluid and in blood of cattle and sheep. Deutch. Tierarztl. Wochenschr. 102:321-323. In German.

Haiying, L., L. Padilla, K. Yoshimatsu, T. Matsui, M. Kitagawa and H. Yano. 2003. Determination of plasma vitamin C concentration in fattening cattle. Anim. Sci. J. 74:7-10.

Hidiroglou, M., M. Ivan and J. R. Lessard. 1977. Effects of ration and inside versus outside housing on plasma levels of ascorbic acid, lactic acid, glucose and cholesterol in Hereford steers wintered under practical conditions. Can. J. Anim. Sci. 57:519529.

Hidiroglou, M., T. R. Batra, M. Ivan M and F. Markham. 1995. Effects of supplemental vitamins $\mathrm{E}$ and $\mathrm{C}$ on the immune responses of calves. J. Dairy Sci. 78:1578-1583.

Hidiroglou, M., T. R. Batra and X. Zhao. 1997. Comparison of vitamin $\mathrm{C}$ bioavailability after multiple or single oral dosing of different formulations in sheep. Reprod. Nutr. Dev. 37:443-448.

Hidiroglou, M. 1999. Technical note: forms and route of vitamin C supplementation for cows. J. Dairy Sci. 82:1831-1833.

Hirooka, H. 2009. The effect of vitamin C supplementation on BMS number in Japanese Black fattening cattle -An approach with meta-analysis-. Bull Beef Cattle Sci. 87:37-40. (in Japanese)

Johnston, C. S., B. L. Beezhold, B. Mostow and P. D. Swan. 2007. Plasma vitamin $\mathrm{C}$ is inversely related to body mass index and waist circumference but not to plasma adiponectin in nonsmoking adults. J. Nutr. 137:1757-1762.

Kawada, T., N. Aoki, Y. Kamei, K. Maeshige, S. Nishiu and E. Sugimoto. 1990. Comparative investigation of vitamins and their analogues on terminal differentiation, from preadipocytes to adipocytes, of 3T3-L1 cells. Comp. Biochem. Physiol. Part A. 96:323-326.

Kleczkowski, M., W. Kluciński, A. Shaktur and J. Sikora. 2005. Concentration of ascorbic acid in the blood of cows with subclinical mastitis. Pol. J. Vet. Sci. 8:121-125.

Knight, C. A., R. A. Dutcher and N. B. Guerrant. 1941. Utilization and excretion of ascorbic acid by the dairy cow. J. Dairy Sci. 24:567-577.

Lykkesfeldt, J. and O. Svendsen. 2007. Oxidants and antioxidants in disease: oxidative stress in farm animals. Vet. J. 173:502511.

MacLeod, D. D., X. Zhang, L. Ozimeck and J. J. Kennelly. 1999. Ascorbyl-2-polyphosphate as a source of ascorbic acid for dairy cattle. Milchwissenschaft 54:123-129.

MacLeod, D., L. Ozimeck and J J. Kennelly. 2003. Supplemental vitamin C may enhance immune function in dairy cows. In: Proceedings of Western Canadian Dairy Seminar, URL, http://www.wcds.ca/proc/1996/wcd96227.htm

May, J. M., Z. C. Qu and S. Mendiratta. 1998. Protection and recycling of $\alpha$-tocopherol in human erythrocytes by intracellular ascorbic acid. Arch. Biochem. Biophys. 349:281289.

McDowell, L. R. 1989. Vitamin C. In: Vitamins in animal nutrition (Ed. L. R. McDowell). Academic Press, New York, USA. pp. 365-387.

McKee, J. S. and P. C. Harrison. 1995. Effects of supplemental 
ascorbic acid on the performance of broiler chickens exposed to multiple concurrent stressors. Poult. Sci. 74:1772-1785.

Miller, J. K. and E. Brezezinska-Slebodzinska. 1993. Oxidative stress, antioxidants and animal function. J. Dairy Sci. 76:28122823.

Mitchell, J. B. and A. Russo. 1983. Thiols, thiol depletion, and thermosensitivity. Radiat. Res. 95:471-485.

Mudron, P., J. Rehage, K. Qualmann, H. P. Sallmann and H. Scholz. 1999. A study of lipid peroxidation and vitamin $\mathrm{E}$ in dairy cows with hepatic insufficiency. J. Vet. Med. Ser. A 46:219-224.

Mori, M., L. Padilla, T. Matsui, H. Yano, Y. Matsui and H. Yamada. 2006. Effects of vitamin C supplementation on plasma vitamin $\mathrm{C}$ level and fattening traits in Japanese Black cattle on a fattening farm. Bull Beef Cattle Sci. 81:15-19. (in Japanese)

Nandan, D., E. P. Clarke, E. H. Ball and B. D. Sanwall. 1990. Ethyl-3,4-dihydrobenzoate inhibits myoblast differentiation: Evidence for an essential role of collagen. J. Cell Biol. 110:1673-1679.

Naresh, R., S. K. Dwivedi, D. Swarup and R. C. Patra. 2002. Evaluation of ascorbic acid treatment in clinical and subclinical mastitis of Indian dairy cows. Asian-Aust. J. Anim. Sci. 15:905-911.

Nockels, C. F. 1988. Immunoenhancing vitamins for cattle. Agri-Practice 9:10-17.

Oohashi, H., H. Takizawa and M. Matsui. 2000. Effect of vitamin $\mathrm{C}$ administration on the improvement of the meat quality in Japanese Black steers. Res. Bull. Aichi Agric. Res. Cent. 32:207-214. (in Japanese)

Padilla, L., K. Shibano, J. Inoue, T. Matsui and H. Yano. 2005. Plasma vitamin $\mathrm{C}$ concentration is not related to the incidence of ketosis in dairy cows during the early lactation period. J. Vet. Med. Sci. 67:883-886.

Padilla, L., T. Matsui, Y. Kamiya, M. Kamiya, M. Tanaka and H. Yano. 2006. Heat stress decreases plasma vitamin C concentration in lactating cows. Livest. Sci. 101:300-304.

Padilla, L., T. Matsui, S. Ikeda, M. Kitagawa and H. Yano. 2007a. The effect of vitamin $\mathrm{C}$ supplementation on plasma concentration and urinary excretion of vitamin $\mathrm{C}$ in cattle. $\mathrm{J}$. Anim. Sci. 85:3367-3370.

Padilla, L., T. Matsui, K. Shibano, H. Katamoto and H. Yano. 2007b. Relationship between plasma vitamin C and serum diagnostic biochemical markers in lactating cows. J. Vet. Med. Sci. 69:909-913.

Palludan, B. and I. Wegger. 1984. Plasma ascorbic acid in calves. In: Ascorbic acid in domestic animals (Ed. I. Wegger, F. J. Tagwerker and J. Moustgaard). Royal Danish Agriculture Society, Copenhagen, Denmark. pp. 131-138.

Ranjan, R., D. Swarup, R. Naresh and R. C. Patra. 2005. Enhanced erythrocytic lipid peroxides and reduced plasma ascorbic acid, and alteration in blood trace elements level in dairy cows with mastitis. Vet. Res. Commun. 29:27-34.

Sahin, K., M. Onderci, N. Sahin, M. F. Gursu and O. Kucuk. 2003. Dietary vitamin $\mathrm{C}$ and folic acid supplementation ameliorates the detrimental effects of heat stress in Japanese quail. J. Nutr. 133:1882-1886.

Sahinduran, S. and M. K. Albay. 2004. Supplemental ascorbic acid and prevention of neonatal calf diarrhoea. Acta Vet. Brno 73:
221-224.

Santos, M. V., F. R. Lima, P. H. Rodrigues, S. B. Barros and L. F. Laranja-Fonseca. 2001. Plasma ascorbate concentrations are not correlated with milk somatic cell count and metabolic profile in lactating and dry cows. J. Dairy Sci. 84:134-139.

Seifi, H. A., M. R. Mokhber Dezfuly and M. Bolurchi. 1996. The effectiveness of ascorbic acid in the prevention of calf neonatal diarrhoea. J. Vet. Med. Series B 43:189-191.

Siegel, B. V. 1975. Enhancement of interferon production by poly(rI)-poly(rC) in mouse cell cultures by ascorbic acid. Nature 254:531-532.

Strombeck, D. R., D. Harrold, Q. Rogers, E. Wheeldon, J. Stern and M. Schaeffer. 1983. Plasma amino acid, glucagon, and insulin concentrations in dogs with nitrosamine-induced hepatic disease. Am. J. Vet. Res. 44:2028-2036.

Styskal, J., H. Van Remmen, A. Richardson and A. B. Salmon. 2012. Oxidative stress and diabetes: What can we learn about insulin resistance from antioxidant mutant mouse models? Free Radic. Biol. Med. 52:46-58.

Sugimoto, T., M. Nakada, M. Fukase, Y. Imai, Y. Kinoshita and T. Fujita. 1986. Effects of ascorbic acid on alkaline phosphatase activity and hormone responsiveness in the osteoblastic osteosarcoma cell line UMR-106. Calcif. Tissue Int. 39:171-174.

Takahashi, E., T. Matsui, S. Wakamatsu, N. Yuri, Y. Shiojiri, R. Matsuyama, H. Murakami, S. Tanaka, S. Torii and H. Yano. 1999. Serum vitamin C concentration in fattening and fattened beef cattle. Anim. Sci. J. 70:J199-J122 (in Japanese)

Tanaka, M., Y. Kamiya, T. Suzuki, M. Kamiya and Y. Nakai. 2008. Relationship between milk production and plasma concentrations of oxidative stress markers during hot season in primiparous cows. Anim. Sci. J. 79:481-486

Torii, S., M. Ohyama, T. Matsui and H. Yano. 1998. Ascorbic acid2-phosphate enhances adipocyte differentiation of cultured stomal vascular cells prepared from bovine perirenal adipose tissue. Anim. Sci. Technol. (Jpn) 69:439-444.

Toutain, P. L., D. Bechu and M. Hidiroglou. 1997. Ascorbic acid disposition kinetics in the plasma and tissues of calves. Am. J. Physiol. 273:R1585-R1597.

Tyler, P. J. and K. A. Cummins. 2003. Effect of dietary ascorbyl-2phosphate on immune function after transport to a feeding facility. J. Dairy Sci. 86:622-629.

Umegaki, K., M. Yoshimura, M. Nishimuta and T. Esashi. 1999. A practical method for determination of vitamin $\mathrm{C}$ in plasma by high-performance liquid chromatography with an electrochemical detector. Jpn Soc. Nutr. Food Sci. 52:107-111. (in Japanese)

Wang, S., I. M. Schram and R. B. Sund. 1995. Determination of plasma ascorbic acid by HPLC method and stability studies. Eur. J. Pharm. Sci. 3:231-239.

Watts, P. S. 1950. Studies on vitamins A and C in bovines; vitamin $\mathrm{C}$ in the liver, kidney and plasma of cows, calves and foetuses. J. Comp. Pathol. 60:283-293.

Weiss, W. P. 2001. Effect of dietary vitamin C on concentrations of ascorbic acid in plasma and milk. J. Dairy Sci. 84:2302-2307.

Weiss, W. P., J. S. Hogan and K. L. Smith. 2004. Changes in vitamin $\mathrm{C}$ concentrations in plasma and milk from dairy cows after an intramammary infusion of Escherichia coli. J. Dairy Sci. 87:32-37. 
Weiss, W. P. and J. S. Hogan. 2007. Effects of dietary vitamin C on neutrophil function and responses to intramammary infusion of lipopolysaccharide in periparturient dairy cows. J. Dairy Sci. 90:731-739.

Wolf, G. 1993. Uptake of ascorbic acid by human neutrophils. Nutr. Rev. 51:337-338.
Wollenberg, P. and W. Rummel. 1987. Dependence of intestinal iron absorption on the valency state of iron. Naunyn Schmiedebergs Arch. Pharmacol. 336:578-582.

Xing, W., A. Singgih, A. Kapoor, C. M. Alarcon, D. J. Baylink and S. Mohan. 2007. Nuclear factor-E2-related factor-1 mediates ascorbic acid induction of osterix expression via interaction with antioxidant-responsive element in bone cells. J. Biol. Chem. 282:22052-22061. 